\title{
Concentrations and potential health hazards of organochlorine pesticides in shallow groundwater of Taihu Lake region, China
}

\author{
Chunfa $\mathrm{Wu}^{\mathrm{a}, *}$, Yongming Luo ${ }^{\mathrm{b}}$, Tong Gui ${ }^{\mathrm{c}}$, Yujuan Huang ${ }^{\mathrm{d}}$ \\ a Department of Agricultural Resources and Environment, Nanjing University of Information Science and Technology, Nanjing 210044, China \\ b Yantai Institute of Coastal Zone Research, Chinese Academy of Sciences, Yantai 264003, China \\ c College of Biology and Environmental Engineering, Jiangsu University of Science and Technology, Zhenjiang 212003, China \\ d Key Laboratory of Soil Environment and Pollution Remediation, Institute of Soil Science, Chinese Academy of Sciences, Nanjing 210008, China
}

\section{H I G H L I G H T S}

- Most of OCP compounds occurred frequently in the shallow groundwater.

- DDTs and HCHs were mainly from the historical residues.

- There are fresh inputs of heptachlor, aldrin and endrin in the shallow groundwater.

- OCPs in the shallow groundwater may be posing serious cancer risks to children.

\section{A R T I C L E I N F O}

\section{Article history:}

Received 5 August 2013

Received in revised form 17 October 2013

Accepted 18 October 2013

Available online 14 November 2013

\section{Keywords:}

Organochlorine pesticides

Composition

Source identification

Cancer risk

Shallow groundwater

\begin{abstract}
A B S T R A C T
A total of 27 shallow groundwater samples were collected from the Taihu Lake region (TLR), to determine the concentrations of 14 organochlorine pesticide (OCP) species, identify their possible sources, and estimate health risk of drinking the shallow groundwater. All OCP species occurred in the shallow groundwater of TLR with high detection frequency except $\mathrm{p}, \mathrm{p}^{\prime}$-dichlorodiphenyldichlorothane ( $\mathrm{p}, \mathrm{p}^{\prime}$-DDD) and $\mathrm{p}, \mathrm{p}^{\prime}$-dichlorodiphenyltrichloroethane ( $p, \mathrm{p}^{\prime}$-DDT). DDTs and hexachlorocyclohexanes $(\mathrm{HCHs})$ were the dominant OCP contaminants in the shallow groundwater of TLR, and they account for $44.2 \%$ total OCPs. The low $\alpha-\mathrm{HCH} / \gamma-\mathrm{HCH}$ ratio, high $\beta-\mathrm{HCH} /$ $(\alpha+\gamma)-\mathrm{HCH}$ ratio and $\beta-\mathrm{HCH}$ being the dominant $\mathrm{HCH}$ isomers for the majority of samples suggest that the HCHs were mainly from the historical use of lindane after a period of degradation. $\mathrm{p}, \mathrm{p}^{\prime}$-DDE being the dominant DDT metabolite for all the samples indicated that the DDTs were mainly from the historical residues. Compositional analysis also suggested that there were fresh input sources of heptachlors, aldrins and endrins in addition to the historical residues. Correlation analysis indicated the hexachlorobenzene (HCB) impurity in the shallow groundwater of TLR was likely from the historical application of lindane and technical $\mathrm{HCH}$ (a mixture of $\mathrm{HCH}$ isomers that is produced by photochlorination of benzene). Carcinogenic risk values for $\alpha-\mathrm{HCH}$, heptachlor, heptachlor epoxide, aldrins and dieldrin in the shallow groundwater in majority area of TLR were found to be $>10^{-6}$, posing a potentially serious cancer risk to those dependant on shallow groundwater for drinking water.
\end{abstract}

(c) 2013 Elsevier B.V. All rights reserved.
Abbreviations: OCP, organochlorine pesticide; POPs, persistent organic pollutants; DDT, dichlorodiphenyltrichloroethane; p, p'-DDE, p, p'-dichlorodiphenylethane; $\mathrm{p}$ $\mathrm{p}^{\prime}$-DDD, $\mathrm{p}, \mathrm{p}^{\prime}$-dichlorodiphenyldichlorothane; $\mathrm{HCB}$, hexachlorobenzene; $\mathrm{HCH}$ hexachlorocyclohexane; US EPA, United State Environmental Protection Agency: TLR, Taihu Lake region; PVC, polyvinyl chloride; PTFE, polytetrafluoroethylene; $\mathrm{SPE}$, solid phase extraction; HPLC, high performance liquid chromatography; GC- $\mu \mathrm{ECD}$ gas chromatography equipped with a ${ }^{63} \mathrm{Ni}$ electron capture detector; MDL, method detection limit; $\mathrm{S} / \mathrm{N}$, signal versus noise value; $C D I$, chronic daily intake; $C$, chemical concentration in water; $I R$, water ingestion rate; $E F$, the exposure frequency; $S F$, slope factor of the contaminant via oral exposure route; $E D$, exposure duration; $B W$, body weight; $A T$, average lifespan; $R$, carcinogenic risk; $H Q$, hazard quotient; $R_{f} D$, reference dose of the contaminant via oral exposure; $\mathrm{CV}$, coefficient of variation HCHs, $\alpha-, \beta-, \gamma-, \delta$-isomers; DDTs, p, p'-DDE, p, p'-DDD and p, p'-DDT; Heptachlors, heptachlor and heptachlor epoxide; Aldrins, aldrin and dieldrin; Endrins, endrin and endrin aldehyde.

* Corresponding author at: Tel./fax: + 862558731539

E-mail address: wchf1680@sina.com (C.Wu).

\section{Introduction}

Organochlorine pesticides (OCPs) are a kind of synthetic chemical pesticides composed primarily of carbon, hydrogen, and chlorine, and they are considered one of the most toxic and persistent organic pollutants (POPs) groups in the environment (Abou-Arab et al., 1995). According to the Stockholm Convention on POPs, nine OCPs(aldrin, chlordane, dichlorodiphenyltrichloroethane (DDT), dieldrin, endrin, heptachlor, mirex, hexachlorobenzene (HCB) and toxaphene) are among the twelve POPs, also known as the dirty dozen. Although hexachlorocyclohexane $(\mathrm{HCH})$ is not included in the Stockholm POPs, it is considered as priority pollutant by the United State Environmental Protection Agency (US EPA) (UNEP, 2003). OCPs attracted wide concern for decades because of their persistence, biomagnification, and high 
toxicity to non-target organisms (Dimond and Owen, 1996; Zhang et al., 2002; Wan et al., 2005). Previous studies have suggested that some OCPs may affect the normal function of the endocrine and reproductive systems of humans and wildlife (Soto et al., 1994; Colborn and Smolen, 1996; Patlak, 1996; Xue et al., 2005). Due to their high persistence and toxic biological effects in the environment, risks of OCPs in a high residual concentration to environment still exists in some regions.

OCPs were widely used in the world from the 1950s, and they are ubiquitous in the environmental matrixes. China is a major agricultural country and a large producer and user of OCPs. Despite the ban on technical DDT (a mixture of DDT isomers that is produced by chloral hydrate, chlorobenzene, and sulfuric acid) and technical HCH (a mixture of $\mathrm{HCH}$ isomers that is produced by photochlorination of benzene) in 1983, dicofol (highly contaminated with DDT compounds) and lindane (almost pure $\gamma-\mathrm{HCH}$ ) have continued to be widely used in agricultural practice in China in recent decades (Li et al., 2006; Yang et al., 2008). OCPs are still routinely found in soil, water, air and even foodstuff in some regions of China such as Taihu Lake region (TLR) (Feng et al., 2003; Qiu et al., 2004; Wang et al., 2007).

There is a substantial body of information about OCP residues in agricultural soils (Zhu et al., 2005; Wang et al., 2007; Zhang et al., 2009), sediments and surface waters of China (Zhang et al., 2002; Zhou et al., 2006; Zhang et al., 2007; Liu et al., 2008; Sun et al., 2008; Chen et al., 2011), and there is a large body of literature on OCP residues in groundwater of other countries such as India, USA, and Portugal (Cerejeira et al., 2003; Sankararamakrishnan et al., 2005; Shukla et al., 2006; Gilliom, 2007; Jayashree and Vasudevan, 2007). However, there is little information about OCP residues in the shallow groundwater of China. Therefore, it is important to investigate the residue concentrations of OCPs in the shallow groundwater because it is an important source of drinking water and to evaluate the potential risks to human health. TLR was an important region for food production where OCPs were most extensively used to increase agricultural production from the 1950s to 1980s (Cai, 1996; Li et al., 1998, 2001; Qiu et al., 2004; Wang et al., 2005). The region is shortage of drinking water for poor surface water and therefore the shallow groundwater as an important source of drinking water. The objectives of the present study were to (1) determine the concentrations and compositions of 14 OCPs including $\alpha-, \beta-$, $\gamma-, \delta-H C H$ and $\mathrm{p}, \mathrm{p}^{\prime}$-dichlorodiphenyldichlorothane ( $\mathrm{p}, \mathrm{p}^{\prime}$-DDD), $\mathrm{p}, \mathrm{p}^{\prime}-$ dichlorodiphenylethane ( $\mathrm{p}, \mathrm{p}^{\prime}$-DDE), $\mathrm{p}, \mathrm{p}^{\prime}$-DDT as well as heptachlor, heptachlor epoxide, HCB, aldrin, diedrin, endrin, endrin aldehyde in the shallow groundwater of TLR, (2) to identify the possible sources of the 14 OCPs in the shallow groundwater, and (3) to estimate human health risk caused by the 14 OCPs through consumption of the shallow groundwater.

\section{Materials and methods}

\subsection{Study area and sampling}

TLR, located between the Yangtze River and the Taihu Lake, is characterized by northern sub-tropical monsoon with a temperate and humid climate throughout the year and four distinct seasons. The average annual temperature is $16.0^{\circ} \mathrm{C}$ and mean annual precipitation is approximately $1181 \mathrm{~mm}$, with most precipitation occurring from May through September. Floodplain, interlaced with a network of canals and ditches, is the dominant geomorphologic type. The shallow aquifer is comprised of unconsolidated sedimentary material. According to hydrogeological data, the thickness of the porous unconfined aquifer is approximately $2-5 \mathrm{~m}$, and the static water table of the shallow groundwater is approximately $1.0-3.0 \mathrm{~m}$ below the ground surface (Chen et al., 2005). The water table fluctuates both with the seasons and years because it is affected by climatic variation and precipitation with the extent of fluctuation reaching $1 \mathrm{~m}$. Shallow groundwater is an important source of drinking water in the study area because of the poor water quality of the surface waters.
A total of 27 shallow groundwater samples were collected from monitoring wells and drinking wells in April 2011 with consideration of uniform distribution, regional difference and convenience of monitoring (the locations are shown in Fig. 1). Most of the wells had depths ranging from 4 to $5 \mathrm{~m}$ while the remaining ranged from 5 to $8 \mathrm{~m}$. The groundwater levels during sampling were $0.7-$ $2.0 \mathrm{~m}$ below the ground surface. Groundwater samples were collected following this sequence:(1) pump the tube-well for several minutes; (2) wash out a clean brown glass bottle with the groundwater; (3) collect groundwater from $5 \mathrm{~cm}$ below the groundwater table using a polyvinyl chloride (PVC) Baylor tube and filter the water through a $0.45 \mu \mathrm{m}$ glass-fiber filter (Whatman, Clifton, NJ, USA) to remove sand and debris; (4) fill a 1-1 brown glass bottle with filtered groundwater and acidify with ultrapure sulfuric acid to $\mathrm{pH}<2$ to inhibit biological activity; (5) seal the bottle using a polytetrafluoroethylene (PTFE) membrane and store the sample in the dark at temperature between $0{ }^{\circ} \mathrm{C}$ and $4{ }^{\circ} \mathrm{C}$ prior to extraction within 2 days. A filtered groundwater sample was collected from each well, and a field duplicate sample was collected for every 5-8 wells to estimate sampling and laboratory analysis precision.

\subsection{Sample extraction and analysis}

The Supelco solid phase extraction (SPE) C18 cartridges (Bellefonte, PA, USA) were first washed with $5 \mathrm{ml}$ of ethyl acetate and conditioned by $5 \mathrm{ml}$ of methanol, then washed with $2 \times 5 \mathrm{ml}$ of ultra-pure water. The filtered groundwater samples $(500 \mathrm{ml})$ were percolated through the cartridges with a flow rate of $5 \mathrm{ml} / \mathrm{min}$ under vacuum pump. After extraction, the pesticides trapped within the cartridges were eluted by passing $6 \mathrm{ml}$ ethyl acetate. Water in the extracts was eliminated by $2.5 \mathrm{~g}$ of anhydrous sodium sulfate (baked at $450^{\circ} \mathrm{C}$ ) before evaporation. The eluates were dried under a gentle stream of nitrogen and pooled together in $1 \mathrm{ml} \mathrm{n}$-hexane.

All reagents used (ethyl acetate, methanol cyclohexane and nhexane) were high performance liquid chromatography (HPLC) grade purchased from Tedia Company, Inc., Fairfield, $\mathrm{OH}$. The anhydrous sodium sulfate (analytical grade, Shanghai Chemical Reagent Co.) was baked at $450{ }^{\circ} \mathrm{C}$ for $4 \mathrm{~h}$.

The OCPs residues were analyzed by a gas chromatography (Varian 3800, Salt Lake City, UT) equipped with a ${ }^{63} \mathrm{Ni}$ electron capture detector (GC- $\mu \mathrm{ECD}$ ) and a DB-5MS (Agilent) column $30 \mathrm{~m} \times 0.25 \mathrm{~mm}$ i.d. and $0.25 \mu \mathrm{m}$ film thickness. Ultra-high purity $\mathrm{N}_{2}$ (>99.9999\%) was used as the carrier gas. The oven temperature program was as follows: injector and detector temperatures were $250{ }^{\circ} \mathrm{C}$ and $300^{\circ} \mathrm{C}$ respectively, initial run temperature was set at $80{ }^{\circ} \mathrm{C}$, ramped at $30^{\circ} \mathrm{C} \mathrm{min}{ }^{-1}$ to $220^{\circ} \mathrm{C}$, then ramped at $5{ }^{\circ} \mathrm{C} \mathrm{min}{ }^{-1}$ to $280{ }^{\circ} \mathrm{C}$ and held for $1 \mathrm{~min}$. The concentrations of OCPs were determined by comparing the peak height of the samples and the calibration curves of the standards. The correlation coefficient of calibration curves of OCPs were all greater than 0.999. Peak identification was conducted by the accurate retention time of each standard $( \pm 1 \%)$ and also confirmed by GC-MS (Aligent 5975).

\subsection{Quality control and quality assurance}

The concentrations of OCPs were quantitatively determined by the external standard method using peak height. For every set of 10 samples, a procedural blank and spike sample consisting of all reagents was run to check for interference and cross contamination. The detection limits of OCPs were determined as the concentration of analyses in a sample that gives rise to a peak with a signal-to-noise ratio $(\mathrm{S} / \mathrm{N})$ of 3 . The pesticides recoveries were determined relative to the ratio of direct injection of extract and the working standards $\left(5 \mu \mathrm{gl}^{-1}\right)$ prepared in n-hexane. The mean recovery of OCPs was estimated at mean 


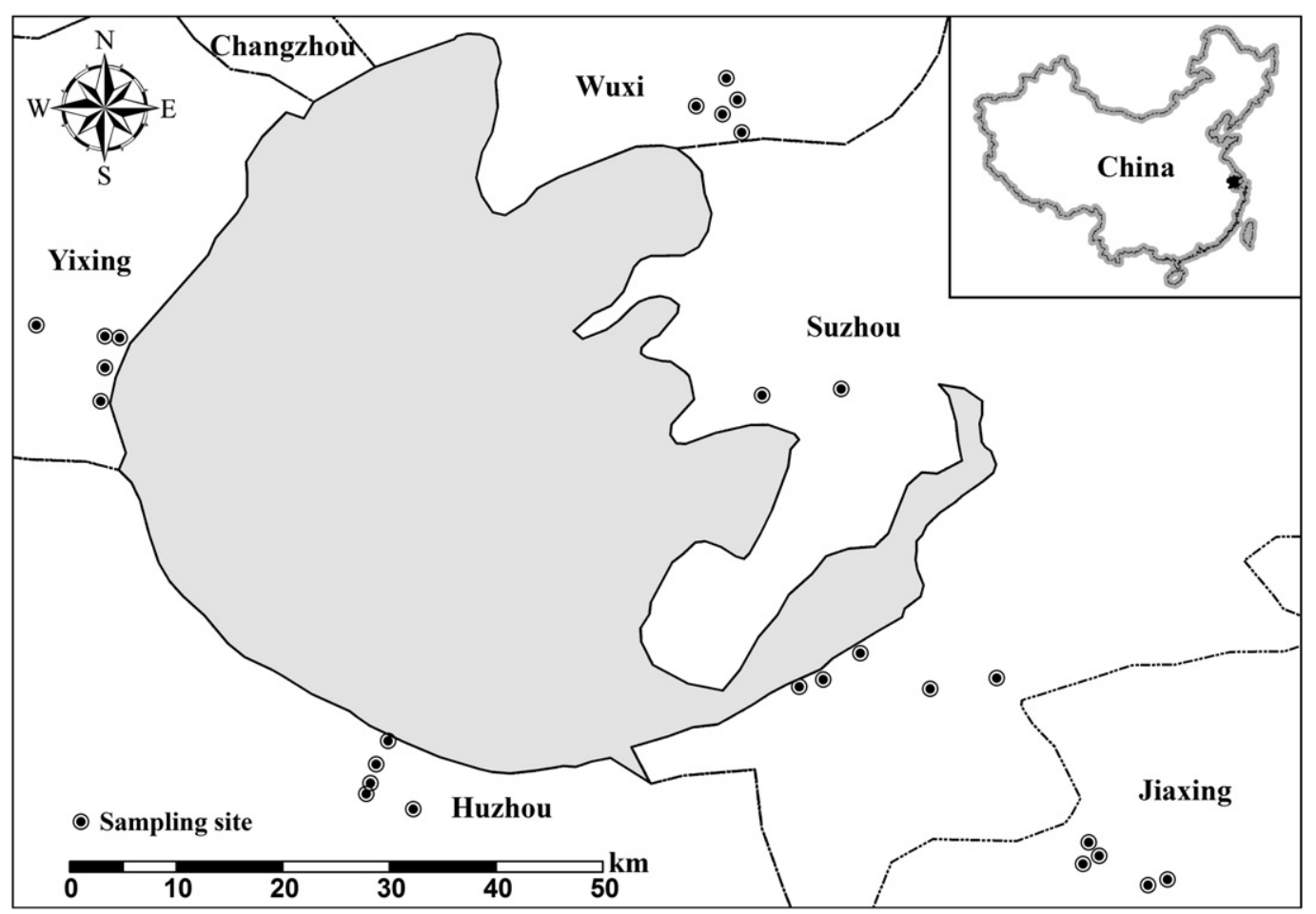

Fig. 1. Study area and locations of sampling sites.

concentration levels. A strict regime of quality control was employed before the onset of the sampling and analysis program. OCPs recovery studies were undertaken to demonstrate the efficiency of the method. The standard solution of the 14 OCPs was purchased from National Research Center of certified reference material in China. Five separate ultra-pure waters were spiked with the working solution $\left(5 \mu \mathrm{g} \mathrm{l}^{-1}\right)$ containing all the 14 OCPs, then extracted and analyzed in the same way as the real samples ( $5 \mathrm{ng} \mathrm{l}^{-1}$ ). Mean recovery of OCPs $(n=5)$ ranged from $78 \%$ to $93 \%$ for water samples. Details on the recovery and method detection limits (MDL) for the 14 OCPs were listed in Table 1.

Table 1

Recoveries and method detection limits (MDL) for the analysis of the 14 organochlorine pesticides by GC- $\mu \mathrm{ECD}{ }^{\mathrm{a}}$

\begin{tabular}{llll}
\hline Pesticide & $\begin{array}{l}\text { Recovery } \\
(\%)\end{array}$ & $\begin{array}{l}\text { RSD } \\
(\%)\end{array}$ & $\begin{array}{l}\text { MDL } \\
\left(\mathrm{ng} \mathrm{l}^{-1}\right)\end{array}$ \\
\hline$\alpha$-HCH & 83 & 4.3 & 0.06 \\
$\beta-\mathrm{HCH}$ & 92 & 2.2 & 0.24 \\
$\gamma$-HCH & 90 & 4.1 & 0.08 \\
$\delta$-HCH & 93 & 1.9 & 0.10 \\
p, $\mathrm{p}^{\prime}$-DDE & 86 & 5.9 & 0.28 \\
p, $\mathrm{p}^{\prime}$-DDD & 84 & 5.7 & 0.54 \\
p, $\mathrm{p}^{\prime}$-DDT & 90 & 3.5 & 0.62 \\
Heptachlor & 79 & 6.2 & 0.35 \\
Heptachlor epoxide & 78 & 4.7 & 0.30 \\
Hexachlorobenzene & 85 & 7.4 & 1.10 \\
Aldrin & 84 & 5.4 & 0.55 \\
Dieldrin & 82 & 3.6 & 0.35 \\
Endrin & 88 & 6.1 & 0.45 \\
Endrin aldehyde & 85 & 4.4 & 0.51 \\
\hline
\end{tabular}

a $\mathrm{RSD}$, relative standard deviation.

\subsection{Health risk assessment model}

Health risk assessment is the process to estimate the nature and probability of adverse health effects in humans who may be exposed to chemicals in contaminated environmental media, now or in the future. Individuals can be exposed to OCPs through several pathways, but oral exposure route is considered to be the most important one (Phan et al., 2010; Hu et al., 2011). In this study, a health risk assessment model derived from US EPA is applied to estimate the carcinogenic and non-carcinogenic risks for adults and children consuming the shallow groundwater as their drinking water source (IRIS, 2005). The chronic daily intake (CDI) is used to estimate human exposure to contaminants (US EPA, 1989), and is calculated using the following formula.

$C D I=\frac{C \times I R \times E F \times E D}{B W \times A T}$

$C=$ chemical concentration in water $\left(\mathrm{mg} \mathrm{l}^{-1}\right) ; I R=$ water ingestion rate $\left(\right.$ lday $^{-1}$ ) (for children: $I R=1.0$; for adults: $I R=2.0$ ); $E F=$ the exposure frequency (350 days year ${ }^{-1}$ ); $E D=$ exposure duration (year) (for children: $E D=6$; for adults: $E D=70$ ); $B W=$ body weight (kg) (for children: $B W=14$; for adults: $B W=60$ ); $A T=$ average lifespan (days) (for children: $A T=2190$; for adults: $A T=25,550$ ).

From the US EPA exposure factors handbook (US EPA, 1997), carcinogenic risk $(R)$ is calculated as follows:

$R=C D I \times S F$

where $C D I$ is the chronic daily intake from the oral exposure route ( $\mathrm{mg} \mathrm{kg}^{-1}$ per day), $S F$ is the slope factor of the contaminant via oral exposure route $\left[\left(\mathrm{mg} \mathrm{kg}^{-1} \text { per day }\right)^{-1}\right]$. 
Table 2

Toxicological parameters of the 14 organochlorine pesticides. ${ }^{\text {a }}$

\begin{tabular}{lll}
\hline Parameter & $S F /\left[\left(\mathrm{mg} \mathrm{kg}^{-1} \text { per day }\right)^{-1}\right]$ & $R_{f} D /\left(\mathrm{mg} \mathrm{kg}^{-1}\right.$ per day $)$ \\
\hline$\alpha$-HCH & 6.3 & $5.0 \mathrm{E}-4$ \\
$\beta$-HCH & 1.8 & $2.0 \mathrm{E}-4$ \\
$\gamma$-HCH & 1.3 & $3.0 \mathrm{E}-4$ \\
$\delta$-HCH & $/$ & $/$ \\
p, $\mathrm{p}^{\prime}$-DDE & 0.34 & $/$ \\
p, $\mathrm{p}^{\prime}$-DDD & 0.24 & $2.0 \mathrm{E}-3$ \\
p, $\mathrm{p}^{\prime}$-DDT & 0.34 & $5.0 \mathrm{E}-4$ \\
Heptachlor & 4.5 & $5.0 \mathrm{E}-4$ \\
Heptachlor epoxide & 9.1 & $1.3 \mathrm{E}-5$ \\
Hexachlorobenzene & 1.6 & $8.0 \mathrm{E}-4$ \\
Aldrin & 17 & $3.0 \mathrm{E}-5$ \\
Dieldrin & 16 & $5.0 \mathrm{E}-5$ \\
Endrin & $/$ & $3.0 \mathrm{E}-4$ \\
Endrin aldehyde & $/$ & $3.0 \mathrm{E}-4$ \\
\hline
\end{tabular}

a /, no given parameter value.

To estimate non-carcinogenic risk, hazard quotient (HQ) is calculated using the following equation:

$H Q=\frac{C D I}{R_{f} D}$

where $R_{f} D$ ( $\mathrm{mg} \mathrm{kg}^{-1}$ per day) is the reference dose of the contaminant via oral exposure route. The values of slope factor and reference dose (Table 2) for OCPs are obtained from the US EPA Integrated Risk Information System (US EPA, 1986).

\section{Results and discussion}

\subsection{Occurrence of OCPs in shallow groundwater}

A summary description of detection frequency (equivalent to the ratio of the number of samples that the pollutant could be detected to the number of analysis samples), range, mean and median concentration for the 14 OCPs in the shallow groundwater is presented in Table 3. ОСР compounds that occurred frequently in the shallow groundwater samples in TLR were HCHs $(\alpha-, \beta-, \gamma-$, and $\delta-\mathrm{HCH}), \mathrm{p}$, $\mathrm{p}^{\prime}$-DDE, heptachlor, heptachlor epoxide, $\mathrm{HCB}$, aldrin, diedrin, endrin and endrin aldehyde. Particularly, HCHs, p, p'-DDE, heptachlor and HCB residues were ubiquitous in the shallow groundwater of TLR, indicating these compounds were very serious in the shallow groundwater of TLR. The detection frequencies of $p, p^{\prime}$-DDD and $p, p^{\prime}$-DDT were relatively low. Although aldrin, dieldrin, endrin, endrin aldehyde and heptachlor epoxide were only from synthetic experiment carried out in China and there was no industrial production (MEP, 2007), these OCP species in the shallow groundwater of TLR had a high detection frequency (77.8\%-96.3\%). Although agricultural use of most OCPs have been banned in China for more than 30 years, these OCPs residues in the shallow groundwater of TLR were very still serious, indicating the persistence of these OCPs in the shallow groundwater is very strong.

Previous studies showed that OCP compounds also occurred frequently in surface water and sediment of Taihu Lake (Yuan et al., 2003; Wang et al., 2012), and indicated that OCPs in the surface water and sediment of Taihu Lake may have influenced the concentrations of OCPs in the shallow groundwater in surrounding area of Taihu Lake. The study area is a floodplain interlaced with a network of canals and ditches, and the shallow groundwater and surface water interactions in the study area are difficult to observe and measure (Chen et al., 2005). To study the impact of the shallow groundwater and surface water interactions on the quality of the shallow groundwater in surrounding area of Taihu Lake, we compared the concentrations of the 14 OCPs in some shallow groundwater samples from the same sub-study area with different distance to Taihu Lake. The results showed that the influence of the interaction on the shallow groundwater quality to some extent was limited (Fig. 2), and the interaction was not the major pathway of OCP entering into the shallow groundwater.

HCHs ( $\alpha-, \beta-, \gamma-$, and $\delta$-isomers) and DDTs ( $p, p^{\prime}-D D E, p, p^{\prime}-D D D$ and $\mathrm{p}, \mathrm{p}^{\prime}$-DDT) could be the most two important contaminants in this area due to their relatively higher fractions in the total OCPs $(21.26 \%$ for $\mathrm{HCHs}$ and 22.94\% for DDTs). The concentrations of the $\mathrm{HCHs}$ and DDTs in the shallow groundwater of TLR had a wide range for HCHs, 11.31-189.4 $\mathrm{ng} \mathrm{l}^{-1}$ with a mean of $43.71 \mathrm{ng} \mathrm{l}^{-1}$; and DDTs, 0.72$482.3 \mathrm{ng} \mathrm{l}^{-1}$ with a mean of $52.46 \mathrm{ng} \mathrm{l}^{-1}$. The concentrations of the other OCPs in the shallow groundwater of TLR also had a wide range with a high coefficient of variation (CV). It indicated that all the 14 OCPs residues in the shallow groundwater of TLR had strong spatial variability.

\subsection{Compositions and source identification of OCPS}

Differences in composition of OCP isomers/metabolites in the environment can reveal different pollution sources (Doong et al., 2002; Zhou et al., 2006) and various ratios have been used to identify the sources of OCPs (Strandberg et al., 1998; Bidleman, 1999; Hong et al., 1999; Covaci and Hurab, 2001). However, the OCPs in groundwater are not derived from direct inputs and the ratios of OCP isomers/metabolites will change during transport due to differences in their physical and chemical properties. Some ratios may be inadequate for the evaluation of old and new sources of OCPs in groundwater despite their widespread use to identify old and new OCP sources in other environment media such as soils, sediments and surface waters.

\subsection{1. $\mathrm{HCHs}$ and $H C B$}

Generally, technical HCH consists of $60-70 \% \alpha-\mathrm{HCH}, 5-12 \% \beta-$ $\mathrm{HCH}, 10-15 \% \gamma-\mathrm{HCH}$, and $6-10 \% \delta-\mathrm{HCH}$ and the $\alpha-\mathrm{HCH} / \gamma-\mathrm{HCH}$ ratio is in the range of 4-7 (Iwata et al., 1993; Buser and Müller,

Table 3

Summary statistics for the concentrations of the 14 organochlorine pesticides ( $\mathrm{ng} \mathrm{l}^{-1}$ ) in the shallow groundwater.

\begin{tabular}{|c|c|c|c|c|c|c|}
\hline Pesticide & Range & Mean & Median & SD & CV (\%) & $\mathrm{DF}(\%)$ \\
\hline$\alpha-\mathrm{HCH}$ & $0.92-41.77$ & 5.85 & 2.71 & 8.13 & 139 & 100 \\
\hline$\beta-\mathrm{HCH}$ & $0.94-107.6$ & 14.53 & 9.60 & 20.13 & 139 & 100 \\
\hline$\gamma-\mathrm{HCH}$ & $1.38-56.05$ & 8.77 & 4.03 & 12.11 & 138 & 100 \\
\hline$\delta-\mathrm{HCH}$ & $3.69-80.58$ & 14.56 & 9.60 & 16.76 & 115 & 100 \\
\hline$\Sigma \mathrm{HCHs}$ & 11.31-189.4 & 43.71 & 30.83 & 35.83 & 88.1 & 100 \\
\hline $\mathrm{p}, \mathrm{p}^{\prime}-\mathrm{DDE}$ & $0.72-453.5$ & 46.77 & 11.89 & 98.84 & 211 & 100 \\
\hline $\mathrm{p}, \mathrm{p}^{\prime}-\mathrm{DDD}$ & BDL-6.95 & 1.04 & $\mathrm{BDL}$ & 2.22 & 212 & 22.2 \\
\hline $\mathrm{p}, \mathrm{p}^{\prime}-\mathrm{DDT}$ & BDL-60.28 & 4.64 & BDL & 12.56 & 270 & 40.7 \\
\hline ¿DDTs & $0.72-482.3$ & 52.46 & 13.18 & 108.9 & 208 & 100 \\
\hline Heptachlor & $4.97-189.2$ & 21.98 & 12.09 & 35.44 & 161 & 100 \\
\hline Heptachlor epoxide & BDL-47.12 & 12.31 & 8.02 & 13.76 & 112 & 96.3 \\
\hline ¿Heptachlors & $5.12-228.9$ & 34.29 & 20.01 & 44.32 & 129 & 100 \\
\hline Hexachlorobenzene & $3.05-65.24$ & 16.53 & 12.43 & 13.40 & 81.1 & 100 \\
\hline Aldrin & BDL-356.5 & 27.59 & 5.61 & 70.06 & 254 & 85.2 \\
\hline Dieldrin & BDL-257.9 & 13.37 & 2.79 & 49.26 & 369 & 77.8 \\
\hline ¿Aldrins & BDL-359.3 & 40.95 & 10.26 & 84.20 & 206 & 96.3 \\
\hline Endrin & BDL-129.2 & 11.53 & 4.79 & 25.08 & 217 & 81.5 \\
\hline Endrin aldehyde & BDL-78.79 & 6.15 & 1.42 & 15.76 & 256 & 74.1 \\
\hline ¿Endrins & $1.04-159.3$ & 17.68 & 5.68 & 33.81 & 191 & 100 \\
\hline Total OCPs & $31.36-1241$ & 205.6 & 104.4 & 272.2 & 132 & 100 \\
\hline
\end{tabular}

a Min, minimum; Max, maximum; SD, standard deviation; $\mathrm{CV}$, coefficient of variation; $\mathrm{DF}$, detection frequency; BDL, below detection limit; $\mathrm{LHCHs}_{\mathrm{s}}$, sum of $\alpha-, \beta-, \gamma$ - and $\delta$ HCH isomers; ¿DDTs, sum of p, p'-DDE, p, p'-DDD and p, p'-DDT; ¿Heptachlors, sum of heptachlor and heptachlor epoxide; ¿Aldrins, sum of aldrin and dieldrin; ¿Endrins, sum of endrin and endrin aldehyde. 
1995; Li and Macdonald, 2005). In contrast, lindane consists almost entirely of $\gamma-\mathrm{HCH}$. The average percentages of $\mathrm{HCH}$ isomers in the shallow groundwater of TLR were $\alpha-\mathrm{HCH}: 13.38 \%, \beta-\mathrm{HCH}: 33.24 \%$, $\gamma-\mathrm{HCH}: 20.06 \%$, and $\delta-\mathrm{HCH}: 33.31 \%$ and the $\alpha-\mathrm{HCH} / \gamma-\mathrm{HCH}$ ratio was in the range of $0.02-3.18$ with a mean of 1.00 . The low $\alpha-\mathrm{HCH} /$ $\gamma-\mathrm{HCH}$ ratio for the majority of groundwater samples collected from TLR were further below the $\alpha-\mathrm{HCH} / \gamma-\mathrm{HCH}$ ratio in technical $\mathrm{HCH}$ (Fig. 3). $\beta-\mathrm{HCH}$ was the predominant $\mathrm{HCH}$ isomers in the shallow groundwater, and the $\beta-/(\alpha+\gamma)-\mathrm{HCH}$ ratio of the $89 \%$ shallow groundwater samples were greater than 0.5 . These observations indicated that the sources of the HCHs were mainly from the historical use of lindane after a period of degradation (Liu et al., 2012), an earlier study also demonstrated lindane was used in this region (Qiu et al., 2004).

HCB has never been used directly as a pesticide in China, but has been used to produce pentachlorophenol (PCP) and pentachlorophenol-Na (PCP-Na), reagent and fireworks (Wei et al., 2007). Most PCP-Na produced through HCB was used as amolluscicide in limnological regions of south China such as Taihu (Wang et al., 2010), and the historical use of PCP-Na may be an important source of HCB in the shallow groundwater of TLR. Previous studies showed that HCB was a trace contaminant in several pesticides containing chlorine such as lindane, technical $\mathrm{HCH}$, pentachlorophenol (PCP) and pentachlorophenol-Na (PCP-Na), pentachloronitrobenzene (PCNB), atrazine, simazine, picloram, chlorothalonil, dimethyl tetrachloroterephthalate (DCPA) (US EPA, 1998; Benazon, 1999; Pacyna et al., 2003; Barber et al., 2005). The Spearman non-parametric correlation coefficients were calculated between $\mathrm{HCB}$ and four $\mathrm{HCH}$ isomers in the shallow groundwater, and the results showed that the concentration of HCB had significant correlation with the concentration of $\alpha-\mathrm{HCH}(\mathrm{r}=0.60)$ and $\beta-\mathrm{HCH}(\mathrm{r}=0.41)$. It indicated that HCB impurity was likely from the historical application of technical $\mathrm{HCH}$ and lindane. It is consistent with the results of earlier studies that the use of PCP-Na and other pesticides containing HCB impurity were the main source of HCB in agricultural soils in TLR (Gao et al., 2005; Wang et al., 2007).

\subsubsection{DDTs}

Among the three DDT isomers/metabolites ( $p, \mathrm{p}^{\prime}$-DDE, $\mathrm{p}, \mathrm{p}^{\prime}$-DDD, and $\mathrm{p}, \mathrm{p}^{\prime}$-DDT) that were analyzed, $\mathrm{p}, \mathrm{p}^{\prime}$-DDE dominated among the DDT isomers/metabolites in the shallow groundwater of TLR, while the other DDT isomers/metabolites ( $\mathrm{p}, \mathrm{p}^{\prime}$-DDD, and $\mathrm{p}, \mathrm{p}^{\prime}$-DDT) had low detection frequency, indicating that historical residues were the main source of DDTs in the shallow groundwater. A higher amount of DDE than DDD in the shallow groundwater of TLR, this probably reflects the aerobic shallow groundwater environment (Vryzas et al., 2009; Sun et al., 2008).

\subsubsection{Heptachlors (heptachlor and heptachlor epoxide)}

Heptachlor is a pesticide primarily used against soil insects and termites although it had also been used in controlling malaria mosquitoes. Heptachlor epoxide is a more stable breakdown product of heptachlor and would normally be assessed together with heptachlor. In the majority (81.5\%) shallow groundwater samples, the concentrations of heptachlor were higher than that of heptachlor epoxide, indicating that there may be some fresh input sources of heptachlor in addition to the historical residues, and the application of heptachlor may have been one of the main fresh input sources of heptachlor in the shallow groundwater of TLR.

\subsubsection{Aldrins (aldrin and dieldrin) and Endrins (endrin and endrin aldehyde)}

Aldrin has been manufactured commercially since 1950 and used to control soil pests and in the protection of wooden structures against termites. It is readily metabolized to dieldrin. There were $18(66.7 \%)$ shallow groundwater samples with a higher concentration of aldrin than that of dieldrin, indicating that there may be some fresh input sources of aldrin in addition to the historical residues, and the application of aldrin may have been one of the main fresh input sources of aldrin in the shallow groundwater of TLR.

Endrin is used against a wide range of agricultural pests and as rodenticide. Endrin may be metabolized to endrin aldehyde and endrin ketone. There were 19(70.4\%) shallow groundwater samples with a higher concentration of endrin than that of endrin aldehyde, indicating that there may be some fresh input sources of endrin in addition to the historical residues, and the application of endrin may have been one of the main fresh input sources of endrin in the shallow groundwater of TLR.

\subsection{Health risk assessment of OCPs in shallow groundwater}

Health risks from drinking local shallow groundwater for adults and children were calculated according to the health risk assessment model (US EPA, 1997). Since the concentrations of the 14 OCPs in the shallow groundwater of TLR had a wide range, the health risk levels caused by the 14 OCPs groups whether for adults or for children through drinking local shallow groundwater also had wide range. Summary statistics for the health risks caused by the 14 OCPs groups for adults and children is presented in Table 4. For adults, the average cancer risks from drinking local shallow groundwater were $1.18 \times 10^{-6}$ for $\alpha-\mathrm{HCH}, 3.16 \times 10^{-6}$ for heptachlor, $3.58 \times 10^{-6}$ for heptachlor epoxide, $1.50 \times 10^{-5}$ for aldrin, $6.84 \times 10^{-6}$ for dieldrin and $3.27 \times 10^{-5}$ for all the OCPs. While for children, the average cancer risks from drinking local shallow groundwater were $2.53 \times 10^{-6}$ for $\alpha-\mathrm{HCH}, 1.79 \times 10^{-6}$ for $\beta-\mathrm{HCH}$, $1.09 \times 10^{-6}$ for $\mathrm{p}, \mathrm{p}^{\prime}$-DDE, $6.78 \times 10^{-6}$ for heptachlor, $7.67 \times 10^{-6}$ for heptachlor epoxide, $1.81 \times 10^{-6}$ for $\mathrm{HCB}, 3.21 \times 10^{-5}$ for aldrin, $1.47 \times 10^{-5}$ for dieldrin and $6.91 \times 10^{-5}$ for all the OCPs.

In the majority of the shallow groundwater samples, cancer risk caused by $\alpha-\mathrm{HCH}$, heptachlor, heptachlor epoxide, aldrin, dieldrin for children and adults through drinking was greater than the acceptable risk level $\left(1 \times 10^{-6}\right)$ recommended by US EPA for carcinogens. This indicated that the current concentrations of these OCPs in the shallow groundwater in majority of the areas of TLR may pose serious cancer risk to the local population, especially to children, and that the shallow groundwater in majority of the areas of TLR was not suitable for drinking water. It is necessary to control the fresh input sources of these OCPs in the shallow groundwater and to carry out valid shallow groundwater remediation. Cancer risk from each pollutant in the shallow groundwater of TLR was in the order of aldrin $>$ dieldrin $>$ heptachlor epoxide $>$ heptachlor $>\alpha$ $\mathrm{HCH}>\mathrm{HCB}>\beta-\mathrm{HCH}>\mathrm{p}, \mathrm{p}^{\prime}-\mathrm{DDE}>\gamma-\mathrm{HCH}>\mathrm{p}, \mathrm{p}^{\prime}-\mathrm{DDT}>\mathrm{p}, \mathrm{p}^{\prime}-\mathrm{DDD}$, the predominance of aldrin and dieldrin suggested that the two OCPs were the main cancer risk factor in the shallow groundwater of TLR. In all the shallow groundwater samples of TLR, cancer risk from $\mathrm{p}, \mathrm{p}^{\prime}$-DDD and $\mathrm{p}, \mathrm{p}^{\prime}$-DDT in the shallow groundwater were lower than the acceptable risk level $\left(1 \times 10^{-6}\right)$ recommended by US EPA for carcinogens, indicating the carcinogenic risk levels caused by them were acceptable.

The HQs of the 14 OCPs through drinking shallow groundwater for individuals were also calculated according to the assessment model. According to the standards (US EPA, 1986), when the ratio exceeds 1 , it means that it has an adverse human health effect. The non-carcinogenic risks from all the 14 OCPs for adults and children were much less than 1 , suggesting that these OCPs in the shallow groundwater of TLR were considered unlikely to pose any noncarcinogenic effects to individuals. Non-carcinogenic risk from each pollutant in the shallow groundwater of TLR was in the order of heptachlor epoxide $>$ aldrin $>$ dieldrin $>\beta-H C H>$ heptachlor $>$ endrin $>\gamma$ $\mathrm{HCH}>\mathrm{HCB}>$ endrin aldehyde $>\alpha-\mathrm{HCH}>\mathrm{p}, \mathrm{p}^{\prime}-\mathrm{DDT}>\mathrm{p}, \mathrm{p}^{\prime}-\mathrm{DDD}$.

In this study, cancer and non-carcinogenic risk assessments utilize the following conventional assumptions regarding human exposure to the 14 OCPs: (1) The shallow groundwater was the sole source of drinking water. This assumption may overestimate health risks for shallow 
groundwater was only one important source of drinking water in the rural area. (2) Risk estimates assume that the concentrations of the 14 OCPs in the shallow groundwater of TLR remain unchanged during the whole exposure duration (6 years for children and 70 years for adults). This assumption could lead to overestimation of potential health risks if pollution levels decline over time. (3) Risk values do not incorporate chemical-specific uptake factors for each pollutant, but rather assume $100 \%$ of the oral dose is absorbed into the body. This could be a source of overestimation of risks. (4) Exposures to the 14 OCPs through other media, such as food and inhalation, are not taken into account. Omission of these exposures may underestimate potential human health risks. These default assumptions are based on science policy decisions to address uncertainties in the risk assessment process. Therefore, the results of cancer and non-carcinogenic risk assessment should not be interpreted as an accurate prediction of observed health outcomes, and it only provide a way to screen for those pollutants
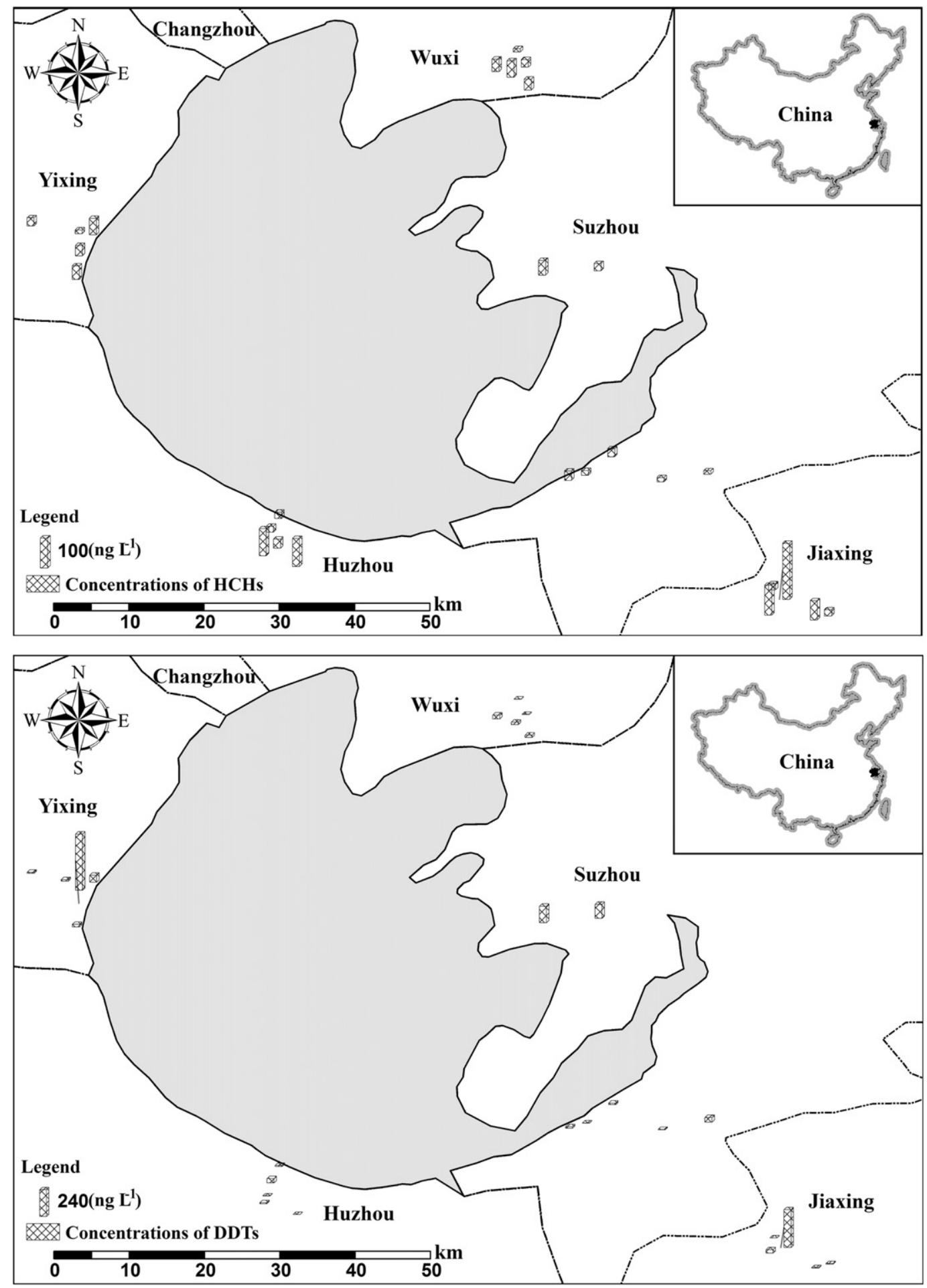

Fig. 2. The column charts of the concentrations of HCHs, DDTs and the 14 organochlorine pesticide (OCPs) in the 27 shallow groundwater samples in the study area. 


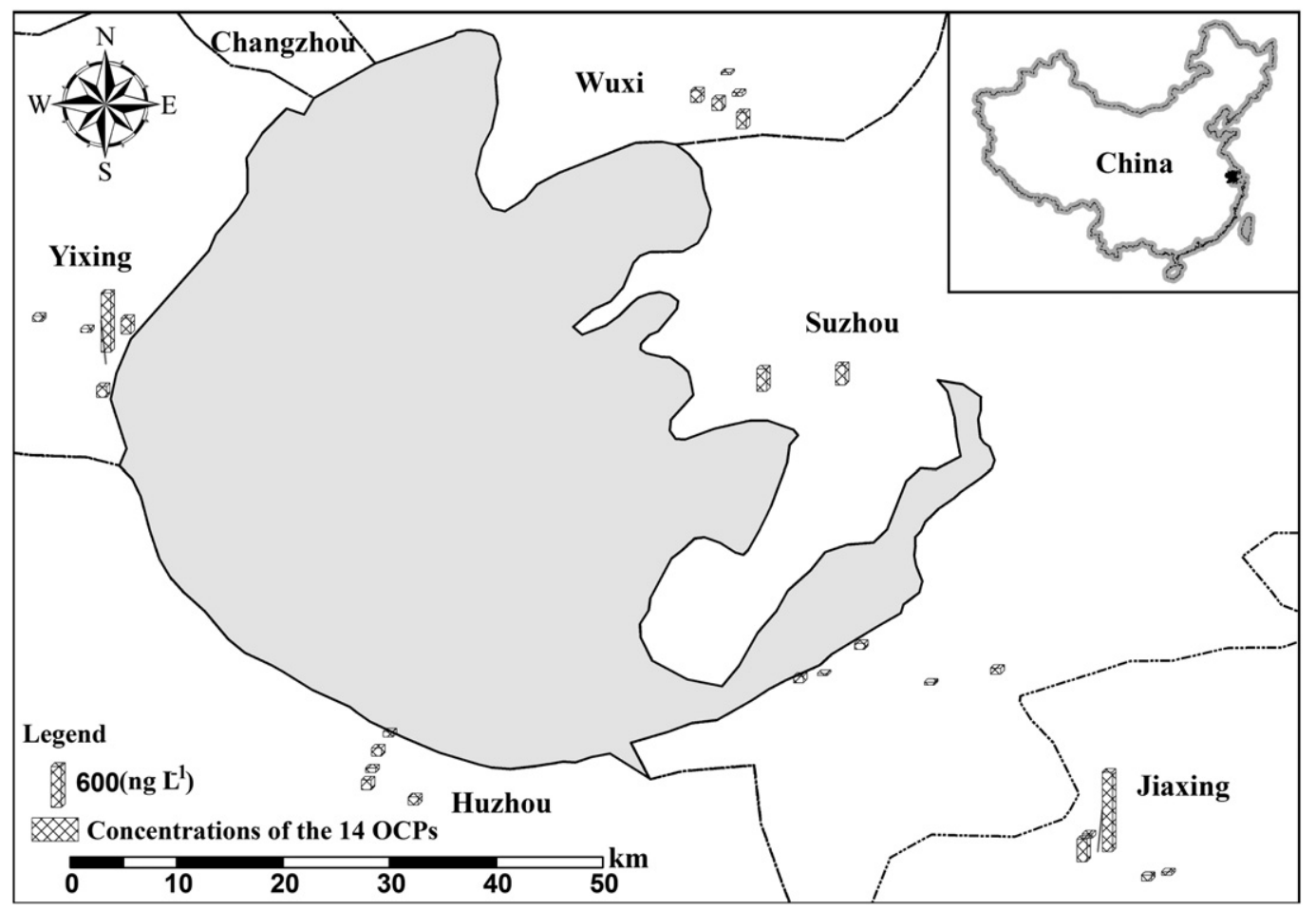

Fig. 2. (continued).

that are of public health significance in order to prioritize research and regulatory intervention efforts.

\section{Conclusion}

OCPs residues in the shallow groundwater of TLR were frequently detected at high concentrations. All OCP species occurred in the shallow groundwater of TLR with high detection frequency except $\mathrm{p}, \mathrm{p}^{\prime}$-DDD and p, $\mathrm{p}^{\prime}$-DDT. DDTs and HCHs were the dominant OCP species in the shallow groundwater of TLR, and they account for $44.2 \%$ total OCPs. Compositional analysis of OCPs indicated that the sources of the HCHs were mainly from the historical use of lindane after a period of degradation; the DDTs were mainly

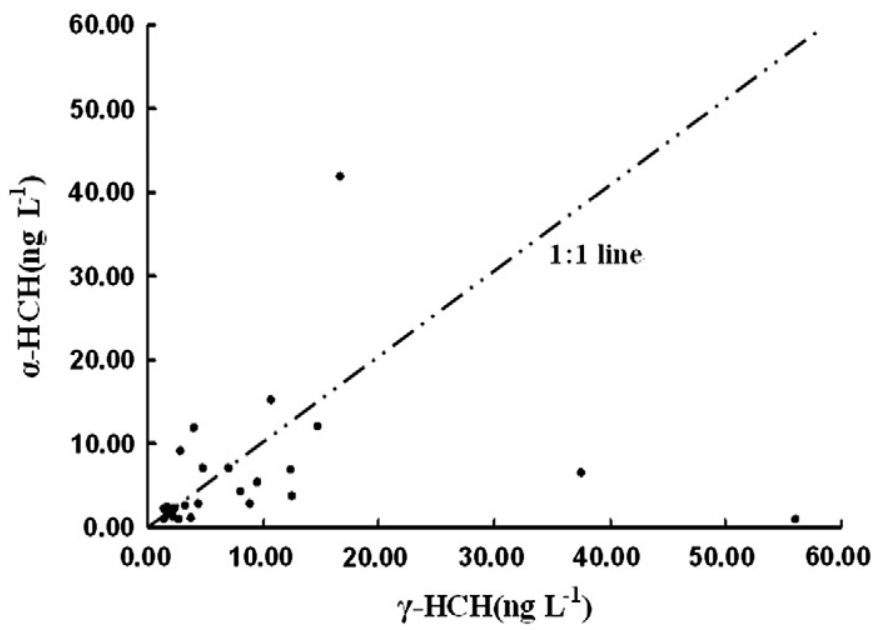

Fig. 3. Concentrations of $\gamma-\mathrm{HCH}\left(\mathrm{ng} \mathrm{l}^{-1}\right)$ versus the concentrations of $\alpha-\mathrm{HCH}\left(\mathrm{ng} \mathrm{l}^{-1}\right)$ in shallow groundwater samples from Taihu Lake Region. from the historical residues; and there were fresh input sources of heptachlors, aldrins and endrins in addition to the historical residues. Correlation analysis indicated that HCB had similar source with $\mathrm{HCHs}$ and the historical application of technical $\mathrm{HCH}$ and lindane containing HCB impurity was one important source of HCB in the shallow groundwater of TLR.

The health risks from drinking local shallow groundwater for adults and children were estimated. The results show the current concentrations of $\alpha-\mathrm{HCH}$, heptachlor, heptachlor epoxide, aldrin, dieldrin in the shallow groundwater in majority of the areas of TLR may pose serious cancer risk to the local population, especially to children, and the aldrin and dieldrin were the main cancer risk factors in the shallow groundwater of TLR. Aldrins, heptachlors and $\mathrm{HCHs}$ residues in the shallow groundwater of TLR should be controlled urgently and effectively.

\section{Conflict of interest}

We are the authors of the manuscript entitled "Levels and potential health hazards of organochlorine pesticides in shallow groundwater of Taihu Lake region, east China", and we declared that no conflict of interest was exited among us.

\section{Acknowledgment}

This research was funded in part by the National Natural Science Foundation of China (Grant No. 41001315), Chinese Academy of Sciences knowledge Innovation Program (Grant No. KZCX2-YW-BR-19) and the Natural Science Foundation of Jiangsu Higher Education Institutions (Grant No. 11KJB170007). We appreciate all the colleagues who collected and analyzed the groundwater samples. The authors are very grateful to Dr. Peter J. Christie of Queen's University Belfast for his contributions to this manuscript. We also extend great appreciation to three anonymous reviewers and Damia Barcelo, co-Editor-in-chief of Science of the Total Environment, for their comments. 
Table 4

Summary statistics for the health risks due to the14 organochlorine pesticides for adults and children in Taihu Lake region through drinking shallow groundwater. ${ }^{\mathrm{a}}$

\begin{tabular}{|c|c|c|c|c|c|c|c|c|}
\hline \multirow[t]{3}{*}{ Pesticide } & \multicolumn{4}{|c|}{ Cancer risk $\left(10^{-6}\right)$} & \multicolumn{4}{|c|}{ Hazard quotient $\left(10^{-2}\right)$} \\
\hline & \multicolumn{2}{|l|}{ Range } & \multicolumn{2}{|l|}{ Mean } & \multicolumn{2}{|l|}{ Range } & \multicolumn{2}{|l|}{ Mean } \\
\hline & Adults & Children & Adults & Children & Adults & Children & Adults & Children \\
\hline$\alpha-\mathrm{HCH}$ & $0.19-8.41$ & $0.40-18.03$ & 1.18 & 2.53 & $0.01-0.27$ & $0.01-0.57$ & 0.04 & 0.08 \\
\hline$\beta-\mathrm{HCH}$ & $0.05-6.19$ & $0.12-13.26$ & 0.84 & 1.79 & $0.02-1.72$ & $0.03-3.68$ & 0.23 & 0.50 \\
\hline$\gamma-\mathrm{HCH}$ & $0.06-2.33$ & $0.12-4.99$ & 0.36 & 0.78 & $0.01-0.60$ & $0.03-1.28$ & 0.09 & 0.20 \\
\hline$\delta-\mathrm{HCH}$ & / & / & / & / & / & / & / & / \\
\hline $\mathrm{p}, \mathrm{p}^{\prime}-\mathrm{DDE}$ & $0.01-4.93$ & $0.02-10.56$ & 0.51 & 1.09 & / & / & / & / \\
\hline $\mathrm{p}, \mathrm{p}^{\prime}-\mathrm{DDD}$ & $0-0.05$ & $0-0.11$ & 0.01 & 0.02 & $0-0.011$ & $0-0.024$ & 0.002 & 0.004 \\
\hline $\mathrm{p}, \mathrm{p}^{\prime}-\mathrm{DDT}$ & $0-0.66$ & $0-1.40$ & 0.05 & 0.11 & $0-0.39$ & $0-0.83$ & 0.03 & 0.06 \\
\hline Heptachlor & $0.71-27.22$ & $1.53-58.32$ & 3.16 & 6.78 & $0.03-1.21$ & $0.07-2.59$ & 0.14 & 0.30 \\
\hline Heptachlor epoxide & $0-13.71$ & $0-29.37$ & 3.58 & 7.67 & $0-11.59$ & $0-24.83$ & 3.03 & 6.48 \\
\hline Hexachlorobenzene & $0.16-3.34$ & $0.33-7.15$ & 0.85 & 1.81 & $0.01-0.26$ & $0.03-0.56$ & 0.07 & 0.14 \\
\hline Aldrin & 0-193.7 & $0-415.1$ & 14.99 & 32.12 & $0-37.98$ & $0-81.38$ & 2.94 & 6.30 \\
\hline Dieldrin & $0-131.9$ & $0-282.6$ & 6.84 & 14.65 & $0-16.48$ & $0-35.32$ & 0.85 & 1.83 \\
\hline Endrin & / & / & / & / & $0-1.38$ & $0-2.95$ & 0.12 & 0.26 \\
\hline Endrin aldehyde & / & / & / & / & $0-0.84$ & $0-1.80$ & 0.07 & 0.14 \\
\hline Total & $1.73-207.9$ & $3.71-445.6$ & 32.26 & 69.12 & $0.18-40.92$ & $0.39-87.7$ & 7.61 & 16.30 \\
\hline
\end{tabular}

a /, no given reference dose of the contaminant via oral exposure route parameter value.

\section{References}

Abou-Arab AAK, Gomma MNE, Badawy A, Naguib Khayria. Distribution of organochlorides pesticide in the Egyptian aquatic ecosystem. Food Chem 1995;54:141-6.

Barber J, Sweetman A, Jones K. Hexachlorobenzene-sources, environmental fate and risk characterization. EuroChlor, Belgium: Science Dossier; 2005.

Benazon N. Hexachlorobenzene emissions/releases inventory for Ontario 1988, 1998 and 2000. Draft Report for Environment Canada; 1999.

Bidleman TF. Atmospheric transport and air-surface exchange of pesticides. Water Air Soil Pollut 1999;115:115-66.

Buser HR, Müller MD. Isomer and enantioselective degradation of hexachlorocyclohexane isomers in sewage sludge under anaerobic conditions. Environ Sci Technol 1995;29: 664-72.

Cai DJ. Pesticide usage in China, prepared for Environment Canada. Environment Canada; 1996.

Cerejeira MJ, Viana P, Batista S, Pereira T, Silva E, Valério MJ, et al. Pesticides in Portuguese surface and ground waters. Water Res 2003;37(5):1055-63.

Chen HH, He JT, Liu F, Liu LC, Li BH. Organic contamination characteristics of shallow groundwater in a study area of the Taihu Lake basin, Jiangsu, China (in Chinese). Geol Bull China 2005;24:735-9.

Chen W, Jin MM, Bu JW, Burnet JE, Qi SH, Ke YB, et al. Organochlorine pesticides in the surface water and sediments from the Peacock River Drainage Basin in Xinjiang, China: a study of an arid zone in Central Asia. Environ Monit Assess 2011;177:1-21.

Colborn T, Smolen MJ. Epidemiological analysis of persistent organochlorine contaminations in cetaceans. Rev Environ Contam Toxicol 1996;146:91-172.

Covaci AC, Hurab PS. Selected persistent organochlorine pollutants in Romania. Sci Total Environ 2001:280:143-52.

Dimond JB, Owen RB. Long-term residue of DDT compounds in forest soils in Maine. Environ Pollut 1996;92:1122-30.

Doong RA, Peng CK, Sun YC, Liao PL. Composition and distribution of organochlorine pesticide residues in surface sediments from the Wu-Shi River estuary, Taiwan. Mar Pollut Bull 2002;45:246-53.

Feng K, Yu BY, Ge DM, Wong MH, Wang XC, Cao ZH. Organochlorine pesticide (DDT and $\mathrm{HCH}$ ) residues in the Taihu Lake Region and its movement in soil-water system I. Field survey of DDT and $\mathrm{HCH}$ residues in ecosystem of the region. Chemosphere 2003;50:683-7.

Gao HJ, Jiang X, Wang F, Bian YR, Wang DZ, Dend JC, et al. Residual levels and new inputs of chlorinated POPs in agricultural soils from Taihu Lake region. Pedosphere 2005;15: 301-9.

Gilliom RJ. Pesticides in US streams and groundwater. Environ Sci Technol 2007;41: 3408-14.

Hong H, Chen W, Xu L, Wang X, Zhang L. Distribution and fate of organochlorine pollutants in the Pearl River Estuary. Mar Pollut Bull 1999;39:376-82.

Hu Y, Qi SH, Zhang JP, Tan LZ, Zhang JQ, Wang YH, et al. Assessment of organochlorine pesticides contamination in underground rivers in Chongqing, Southwest China. J Geochem Explor 2011;111:47-55.

IRIS (Integrated Risk Information System). Cincinnati, OH: US Environmental Protection Agency; 2005 [URL: http://www.epa.gov/iris].

Iwata $\mathrm{H}$, Tanabe N, Sakai N, Tatsukawa R. Distribution of persistent organochlorines in the oceanic air and surface seawater and the role of ocean on their global transport and fate. Environ Sci Technol 1993:27:1080-98.

Jayashree R, Vasudevan N. Organochlorine pesticide residues in ground water of Thiruvallur district, India. Environ Monit Assess 2007;128:209-15.

Li YF, Macdonald RW. Sources and pathways of selected organochlorine pesticides to the Arctic and the effect of pathway divergence on $\mathrm{HCH}$ trends in biota: a review. Sci Total Environ 2005;342:87-106.

Li YF, Cai DJ, Singh A. Technical hexachlorocyclohexanes use trends in China and their impact on environment. Arch Environ Contam Toxicol 1998;35:688-97.
Li YF, Cai DJ, Shan ZJ, Zhu ZL. Gridded usage inventories of technical hexachlorocyclohexane and lindane for China with $1 / 6^{\circ}$ latitude by $1 / 4^{\circ}$ longitude resolution. Arch Environ Contam Toxicol 2001;41:261-6.

Li J, Zhan G, Qi S, Li X, Peng X. Concentrations, enantiomeric compositions, and sources of $\mathrm{HCH}, \mathrm{DDT}$ and chlordane in soils from the Pearl River Delta, South China. Sci Total Environ 2006;372:215-24.

Liu M, Cheng S, Ou D, Yang Y, Liu H, Hou L, et al. Organochlorine pesticides in surface sediments and suspended particulate matters from the Yangtze Estuary, China. Environ Pollut 2008;156:168-73.

Liu WX, He W, Qin N, Kong ZZ, He QS, Ouyang HL, et al. Residues, distributions, sources, and ecological risks of OCPs in the water from Lake Chaohu, China. Scientific World Journal 2012. http://dx.doi.org/10.1100/2012/897697.

MEP (Ministry of Environment Protection of the People's Republic of China). National implementation plan for the Stockholm Convention on persistent organic pollutants: 2007.

Pacyna JM, Breivik K, Munch J, Fudala J. European atmospheric emissions of selected persistent organic pollutants, 1970-1995. Atmos Environ 2003;37:119-31.

Patlak M. Estrogens may link pesticides, breast cancer. Environ Sci Technol 1996;30: 210-1.

Phan K, Sthiannopkao S, Kim KW, Wong MH, Sao V, Hashim JH, et al. Health risk assessment of inorganic arsenic intake of Cambodia residents through groundwater drinking pathway. Water Res 2010;44:5777-88.

Qiu XH, Zhu T, Jing L, Pan HS, Li QL, Miao GF, et al. Organochlorine pesticides in the air around the Taihu Lake, China. Environ Sci Technol 2004:38:1368-74.

Sankararamakrishnan N, Sharma AK, Sanghi R. Organochlorine and organophosphorous pesticide residues in ground water and surface waters of Kanpur, Uttar Pradesh, India. Environ Int 2005;31:113-20.

Shukla G, Kumar A, Bhanti M, Joseph PE, Taneja A. Organochlorine pesticide contamination of ground water in the city of Hyderabad. Environ Int 2006;32:244-7.

Soto AM, Chung KL, Sonnenshein C. The pesticides endosulfan, toxaphene and dieldrin have estrogenic effects on human estrogen-sensitive cells. Environ Health Perspect 1994;102:380-3.

Strandberg B, van Bavel B, Bergvist PA, Bronman D, Ishaq R, Näf C, et al. Occurrence, sedimentation, and spatial variations of organochlorine contaminants in settling partculate matter and sediments in the northern part of the Baltic Sea. Environ Sci Technol 1998;32:1754-9.

Sun JH, Feng JL, Liu Q Li QL. Distribution and sources of organochlorine pesticides (OCPs) in sediments from upper reach of Huaihe River, East China. J Hazard Mater 2008;184: 141-6.

UNEP (United Nations Environment Programme). Regionally based assessment of persistent toxic substances. Global Report. Geneva: UNEP Chemicals; 2003.

US EPA. Guidelines for the health risk assessment of chemical mixtures. Washington DC: Office of Emergency and Remedial Response; 1986

US EPA. Risk assessment guidance for Superfund. Volume I: human health evaluation manual (part A), EPA/540/1-89/002. Washington, DC: Office of Emergency and Remedial Response; 1989.

US EPA. Exposure factors handbook, EPA/600/P-95/002Fa. Washington, DC: Office of Research and Development National Center for Environmental Assessment; 1997.

US EPA. 1990 Emissions inventory of section 112 (c) (6) pollutants: polycyclic organic matter (POM), TCDD, TCDF, PCBs, hexachlorobenzene, mercury and alkylated lead. Final Report; 1998.

Vryzas Z, Vassiliou G, Alexoudis C, Papadopoulou-Mourkidou E. Spatial and temporal distribution of pesticide residues in surface waters in northeastern Greece. Water Res 2009;43:1-10

Wan Y, Hu J, Liu J, An W, Tao S, Jia Z. Fate of DDT-related compounds in Bohai Bay and its adjacent Haihe Basin, North China. Mar Pollut Bull 2005;50:439-45.

Wang TY, Lu YL, Zhang H, Shi YJ. Contamination of persistent organic pollutants (POPs) and relevant management in China. Environ Int 2005;31:813-21. 
Wang F, Jiang X, Bian YR, Yao FX, Gao HJ, Yu GF, et al. Organochlorine pesticides in soils under different land usage in the Taihu Lake region, China. J Environ Sci (China) 2007;19:584-90.

Wang G, Lu YL, Han JY, Luo W, Shi YJ, Wang TY, et al. Hexachlorobenzene sources, levels and human exposure in the environment of China. Environ Int 2010;36:122-30.

Wang XQ Xu J, Guo CS, Zhang Y. Distribution and sources organochlorine pesticides in Taihu Lake, China. Bull Environ Contam Toxicol 2012;89:1235-9.

Wei DB, Kameya T, Urano K. Environmental management of pesticidal POPs in China: past, present and future. Environ Int 2007;33:894-902.

Xue N, Wang H, Xu X. Progress in study on endocrine disrupting pesticides (EDPs) in aquatic environment (in Chinese). Chin Sci Bull 2005;50:2257-66.

Yang XL, Wang SS, Bian YR, Chen F, Yu GF, Gu G, et al. Dicofol application resulted in high DDTs residue in cotton fields from northern Jiangsu province, China. J Hazard Mater 2008; $150: 92-8$
Yuan XY, Wang Y, Chen J, Sun C, Xu NZ. Organochlorine residues of sediments in Taihu Lake and its risk evaluation (in Chinese). Environ Sci 2003;24(1):121-5.

Zhang G, Parker A, House A, Mai B, Li X, Kang Y, et al. Sedimentary records of DDT and HCH in the Pearl River Delta, South China. Environ Sci Technol 2002;36:3671-7.

Zhang G, Li J, Cheng H, Li X, Xu W, Jones KC. Distribution of organochlorine pesticides in the northern South China Sea: implications for land outflow and air-sea exchange. Environ Sci Technol 2007;41:3884-90.

Zhang HB, Luo YM, Li OB. Burden and depth distribution of organochlorine pesticides in the soilprofiles of Yangtze River Delta Region, China: Implication for sources and vertical transportation. Geoderma 2009;153:69-75.

Zhou RB, Zhu LZ, Yang K, Chen YY. Distribution of organochlorine pesticides in surface water and sediments from Qiantang River, East China. J Hazard Mater 2006;137:68-75.

Zhu YF, Liu H, Xi ZQ Cheng HX, Xu XB. Organochlorine pesticides (DDTs and HCHs) in soils from the outskirts of Beijing, China. Chemosphere 2005;60:770-8. 